\title{
Correspondence
}

\section{Respiratory depression and spinal opioids}

To the Editor:

We would like to congratulate Etches et al. for their review article on respiratory depression and spinal opioids. ${ }^{1}$

There are several comments we would like to make regarding this paper and also about the use of intraspinal opioids in general. The first recorded use of intraspinal opioids was actually reported from Japan in $1901 .{ }^{2}$ An injection of $10 \mathrm{mg}$ of Morphine combined with $20 \mathrm{mg}$ of Eucaine, a local anaesthetic, was made into the subarachnoid space of two patients with uncontrollable back pain. Both obtained excellent pain relief lasting several days.

We agree with the authors that the value of spinal opioids in the management of postoperative pain is unproven. However, as we all know, the present methods available to us for the provision of postoperative pain relief leave a lot to be desired. ${ }^{3}$ Pain following surgery is usually worse in the first 24 hours. It is during this period that the single intrathecal dose of an opiate would be most useful. At this hospital, we are at present undertaking a small trial using a single dose of intrathecal diamorphine $(2.5 \mathrm{mg}$ ) given at the start of surgery in patients undergoing major urological or vascular surgery. All the patients are monitored in ITU for up to 36 hours. The results in six patients (two urological and four vascular) so far studied have been very encouraging.

The tracheas of the six patients studied in this small pilot trial were all extubated immediately after completion of the surgery. None of them was given systemic opiates preoperatively or intraoperatively. None of the patients complained of itching or headache. However, as their bladders were catheterised, it is difficult to say whether or not they would have had urinary retention. None of the patients required any form of analgesia in the first 24 hours. (Postoperatively they were charted down to receive codeine phosphate $30-60 \mathrm{mg}$ intramuscularly four hourly on a PRN basis.)

We are now undertaking a more formal trial regarding the use of intrathecal diamorphine, after obtaining these very encouraging results.

In the ideal world, if all postoperative patients could be monitored in special postoperative wards by trained nursing staff, the use of intraspinal opioids could become more widespread.

\author{
A. Ravalia MB FFARCS \\ P.N. Robinson MB FFARCS \\ Edgware General Hospital, \\ Middx, England
}

\section{REFERENCES}

1 Etches $R C$, Sandler $A N$, Daley MD. Review article: respiratory depression and spinal opioids. Can J Anesth 1989; 36: 165-85.

2 Matsuki A. Nothing new under the sun - a Japanese pioneer in the clinical use of intrathecal morphine (Editorial). Anesthesiology 1983:58: 289-90.

3 Benedetti C, Bonica $J$, Belluci $G$. Pathophysiology and therapy of postoperative pain: a review. In: Benedetti C. Chapman CR, Morica A Eds. Advances in Pain Research and Therapy, Vol, 7, Recent Advances in the Management of Pain. New York, Raven Press, 1984: $373-407$.

\section{REPLY}

We would like to thank Doctors Ravalia and Robinson for their interest in our article, and for drawing our attention to the much earlier use of intrathecal morphine. We certainly agree with the statement that the present management of postoperative pain is imperfect, and we do not suggest the avoidance of spinal opioids; in many patients they will provide excellent analgesia. However, we feel that before these techniques are endorsed as a "goid standard" for analgesia, we first need to see good, controlled, blinded studies which compare equianalgesic doses of the opioid in question administered intravenously, epiduraily, or intrathecally. At present there are few studies that indicate that the approaches differ in the degree of sedation or respiratory depression produced if equivalent analgesia is obtained.

The use of intrathecal diamorphine poses some interesting pharmacokinetic questions. Diamorphine in solution at $37^{\circ} \mathrm{C}$ deacetylates spontaneously to 6-acetylmorphine and morphine, and in brain homogenates diamorphine may be completely converted to its metabolites within 20 minutes, In addition. diamorphine itself may be inactive at opioid receptors, and any analgesic activity may be due to its primary metabolites. ${ }^{2}$ With these points in mind, it is unclear how the effects of intrathecal diamorphine will differ from those of the same dose of intrathecal morphine.

Finally, we would like to caution practioners who are considering the epidural or intrathecal use of drugs not yet approved for such routes of administration. Before using such drugs clinically it is the practitioner's responsibility to ensure that animal toxicity studies have been completed with a favourable outcome, and that approval from the appropriate government agency (in Canada, the Health Protection Branch) has been obtained. 


\section{R.C. Etches $M D$}

Department of Anaesthesia

University of Alberta, Edmonton

A.N. Sandler MB ChB

Department of Anaesthesia

University of Toronto, Toronto

\section{REFERENCES}

1 Sandler AN, Chovaz, $P$, Whiting W. Respiratory depression following epidural morphine: a clinical study. Can Anaesth Soc J 1986; 33: 542-9.

2 SawynokJ. The therapeutic use of heroin: a review of the pharmacological literature. Can J Physiol Pharmacol 1986; $64: 1-6$.

\section{Metoclopramide inhibits plasma cholinesterase}

To the Editor:

We read with interest the paper by Kambam $e t$ al. noting the inhibition of plasma cholinesterase by metoclopramide in vitro. ' However, we feel that their observations may not justify their conclusions concerning the clinical relevance of this interaction. Their experimental method was based on creating specific concentrations of metoclopramide in the cholinesterase reaction mixture ${ }^{2}$ and they succeeded in demonstrating increasing inhibition of enzyme activity with increasing metoclopramide concentrations. Unfortunately they appear to have confused in vivo therapeutic levels of metoclopramide with the in vitro concentrations used in their study. To produce concentrations in plasma similar to the in vitro metoclopramide concentrations described by the authors the concentration would need to be 30 times that stated in the reaction mixture since only $0.1 \mathrm{ml}$ of plasma was used in a total reaction volume of $3 \mathrm{ml}$. Thus a plasma concentration of $0.14 \mu \mathrm{g} \cdot \mathrm{ml}^{-1}$ (their quoted normal peak plasma level of metoclopramide after a $10 \mathrm{mg}$ dose) would produce such a low concentration in the reaction mixture $\left(0.005 \mu \mathrm{g} \cdot \mathrm{ml}^{-1}\right.$ approximately) that enzymatic inhibition would be insignificant. We feel that this pharmacological phenomenon is unlikely to be of clinical significance at normal clinical doses of metoclopramide, although the larger doses used in counteracting the emetic effects of cancer chemotherapy may result in some degree of plasma cholinesterase inhibition.

If this interpretation is correct, it would also cast doubt on the interpretations in an earlier paper by the primary author describing the inhibitory effect of procainamide on plasma cholinesterase activity in vitro with an identical protocol, and extrapolating this to clinical situations. ${ }^{3}$
S. G. Graham MBChB

A. M. Burgess BSc

Departments of Anaesthetics and Clinical Chemistry

City Hospital Hucknall Road Nottingham

England NG5 1PB

\section{REFERENCES}

1 Kambam JR, Parris CU, Franks JJ, Sastry BVR, Naukam $R$, Smith $B E$. The inhibitory effect of metoclopramide on plasma cholinesterase activity. Can J Anaesth 1988; 35: 476-8.

2 Zapf PW, Coghlan CHM. A kinetic method for the estimation of pseudocholine esterase using naphthyl acetate substrate. Clin Chim Acta 1974; 43: 237-42.

3 Kambam JR, Naukam RI, Sastry BVR. The effect of procainamide on plasma cholinesterase activity. Can J Anaesth 1987; 34: 579-81

\section{REPLY}

We previously reported the in vitro effect of metoclopramide on plasma cholinesterase (PCHE) activity.' Our data showed that PCHE activity was significantly reduced by metoclopramide at all concentrations studied $(P<0.001)$. We recommended caution when succinylcholine and/or ester fype local anaesthetics are administered to patiens who are also receiving metoclopramide, especially in high doses. A recent study by Kao and Turner using an entirely different PCHE assay showed a similar decrease in PCHE activiny by metoclopramide ${ }^{2}$ Kao and Turner also showed a significant prolongation of succinylcholine action by meroclopramide in their patients.

We used a kinetic method described by Zapf and Coghlan in the determination of PCHE activity and dibucaine numbers. ${ }^{3}$ Metoclopramide was added to the reaction mixture to give a final concentration of $0.05,0.1,0.5,1.0,2.5$, and 5.0 $\mu \mathrm{g} \cdot \mathrm{ml}^{-I}$. The reaction was started with the addition of $0.1 \mathrm{ml}$ of plasma and the resulting PCHE activity was expressed as units $\cdot \mathrm{ml}^{-1}$ of plasma. Our in vitro concentrations of metoclopramide were designed to reflect the in vivo concentrations of metoclopramide to which the PCHE is exposed. When the effect of inhibitors on PCHE activiry is studied in vitro, it is the final concentration of the inhibitor in the reaction mixture that is commonly reported. For example the effects of dibucaine (Dibucaine number) and fluoride (Fluoride number) are studied and expressed in this manner ${ }^{3-4} A n$ in vivo study presents a somewhat different problem with dilution. The small amount of plasma taken from the patients receiving metoclopramide is diluted several times in the reaction mixture. This in turn yields a spuriously higher than expected PCHE activity and would not reflect the in vivo effect of the inhibitor on PCHE activify.

In summary we think the method we used is correct. We also believe that when the effect of drugs on PCHE activity zzeeds to be determined, an in vitro study is probably superior to an in vivo study. Finally, the significance of in vitro findings of $P C H E$ inhibition can be determined clinically by studying the duration of succinylcholine action in patients receiving inhibitor drugs.

\section{REFERENCES}

1 Kambam JR, Parris WCV, Franks JJ, Sastry BVR Naukam $R J$, Smith $B E S$. The inhibitory effect of 